\title{
Kinetic Aspects of Gold and Silver Recovery in Cementation with Zinc Power and Electrocoagulation Iron Process
}

\author{
Gabriela V. Figueroa Martinez ${ }^{1}$, José R. Parga Torres ${ }^{1}$, Jesús L. Valenzuela García ${ }^{2}$, \\ Guillermo C. Tiburcio Munive ${ }^{2}$, Gregorio González Zamarripa ${ }^{1}$ \\ ${ }^{1}$ Department of Metallurgy and Materials Science, Institute of Technology of Saltillo, Saltillo, México \\ ${ }^{2}$ Department of Chemical Engineering and Metallurgy, University of Sonora, Hermosillo, México \\ Email: jrparga@its.mx
}

Received February 11, 2012; revised March 16, 2012; accepted March 29, 2012

\begin{abstract}
The Merrill-Crowe or Cementation process is used for concentration and purification of gold and silver from cyanide solutions. Among other available options for recovery of precious metals from cyanide solutions, Electrocoagulation (EC) is a very promising electrochemical technique for the recovery of this precious metals. In this work first, an introduction to the fundamentals of the Merrill Crowe and EC process are given, then Kinetic aspects conditions and results of the both process, for the removal of gold and silver from cyanide solutions are presented, and finally the characterization of the solid products formed during the EC process with X-ray Diffraction and SEM are shown. Results suggests that The cementation of both gold and silver by suspended zinc particles conforms to well-behaved fist order kinetics and for the EC process the results show that is an excellent option to remove Au and Ag from cyanide solution by using iron electrodes. Finally, $99.5 \%$ of gold and silver were removed in the experimental EC reactor, and it was achieved in 5 minutes or less.
\end{abstract}

Keywords: Cyanidation; Merrill Crowe; Electrocoagulation; Kinetics

\section{Introduction}

Cyanide leaching processes have been used by the mining industry for over 150 years in the extraction of noble metals, the popularity of cyanidation is based mostly on the simplicity of the process. Elsner in Germany in 1846 studied the dissolution of gold in cyanide aqueous solution and noted that atmospheric oxygen played an important role during dissolution of gold [1]. Also, sodium cyanide in an alkaline solution is a strong solvent for gold and silver, most mill operators use it to dissolve fine gold particles with a practical maximum size is no greater than 50 microns. In most cyanidation operations, the gold particles require 24 to $72 \mathrm{hr}$ for complete dissolution in slurry or pulp of about 50 percent solids. Extremely large leaching reactors known as Pachuca tank in with the finely ground ore was agitated with the alkaline cyanide leaching agent and equipped with compressed air injection in the pulp had been designed to dissolve the gold and silver. It is widely accepted that the gold cyanidation process can be represented by the classic Elsner's Equation (1). The mechanism and kinetics have been discussed in several papers and reviews [1,2].

$$
4 \mathrm{Au}+8 \mathrm{CN}^{-}+\mathrm{O}_{2}+2 \mathrm{H}_{2} \mathrm{O}=4 \mathrm{Au}(\mathrm{CN})_{2}+4 \mathrm{OH}^{-}
$$

Silver, similarly, dissolves readily in dilute cyanide solutions in the presence of oxygen. However, since silver in Mexicans ores occurs as argentite the cyanidation and sulphide oxidation reaction are as follows:

$$
\begin{gathered}
\mathrm{Ag}_{2} \mathrm{~S}+4 \mathrm{CN}^{-}=2 \mathrm{Ag}(\mathrm{CN})_{2}^{-}+\mathrm{S}^{2-} \\
\mathrm{S}^{2-}+\mathrm{CN}^{-}+\frac{1}{2} \mathrm{O}_{2}+\mathrm{H}_{2} \mathrm{O}=\mathrm{CNS}^{-}+2 \mathrm{OH}^{-}
\end{gathered}
$$

The cyanide concentration determines the rate of anodic gold dissolution while the oxygen reduction rate is dependent on the concentration of dissolved oxygen. In the cyanidation process, free cyanide ions in solution can be provided only at $\mathrm{pH}>9.3$. The $\mathrm{pH}$ of the pulp can be increased with the additions of alkali hydroxides $(\mathrm{NaOH}$, $\mathrm{KOH}, \mathrm{Ca}(\mathrm{OH})_{2}$, etc.), known as proactive alkalis. Also, details of this electrochemical reaction have received considerable attention and under certain circumstances the reaction is limited by the coupled diffusion of $\mathrm{CN}^{-}$ and $\mathrm{O}_{2}$ to the gold surface.

Lixiviation of undesirable base metals, such as copper, 
iron and arsenic, reduces the efficiency of the process by consuming additional reagents, and necessitates further processing to remove these contaminants [3].

Actually, the two conventional processes for gold and silver recovery from cyanide leach solution are: the Merrill Crowe zinc dust cementation and the carbon adsorption process. In the first process, the efficiency of the reaction is significantly improved by removing dissolved oxygen from the system prior to zinc addition, using a vacuum deaeration technique. This reaction of cementation is sensitive to suspend solids in the leach solution and thus requires solution clarification before cementation. In the activated carbon process, the precious metals are absorbed onto granules of carbon and after loading, they are then stripped of the loaded gold by a hot causticcyanide solution. Then, the cathodes from the carbon adsorption process or the precipitates from the Merrill Crowe process (metal displacements) are then melted in crucible furnaces along with fluxing materials such as borax, niter and silica. The resultant product from smelting is Dore bullion of precious metals typically analyzing more than 95 percent of precious metals.

Each recovery method has advantages and disadvantages. Process selection depends on the specific conditions for particular operation and the facilities already available. Another new process is the Electrocoagulation (EC) technology and has recently been reviewed as an alternative for gold and silver recovery from alkaline cyanide solutions [3]. The EC process is a very promising technique for the recovery of precious metals such as silver and gold: EC needs no chemical reagents, does not generate toxic materials requiring special disposal and this also make it an ecologically viable technique. Literature reviewing showed that the potential of EC as an alternative to traditional treatment recovery of precious metals (silver and gold cyanide) has not yet been exploited.

\subsection{The Merrill Crowe Process or Cementation Technology}

The term cementation comes from a Spanish word meaning "precipitation". This term was first used in 1500 to describe a process for the recovery of copper from aqueous solutions at Rio Tinto in Spain. However, cementation of a noble metal from solution by means of more base, or electronegative, metal has been practiced since ancient times [4]. Near the beginning of the fourth century, Zosimos stated that, when iron is immersed in a solution of a copper salt, it acquires a coating of copper. In the sixteenth century, Paracelsus precipitated silver from silver nitrate by inserting a plate of copper in the solution, and he noted that the copper dissolved. Bergman, in this "De Precipitates Metallics", in the mid- eighteenth century, observed that the metals precipitate one on another after a certain order of nobility: zinc, iron, lead, tin, copper, silver and gold.

Then, cementation reactions, variously know as metaldisplacement reactions or contact-reduction reactions, are processes in which a metal ion in a solution is reduced to the elemental metallic state with the concurrent oxidation of a more electronegative metal placed into the same solution. This process is one of the most ancient, yet economical and efficient, hydrometallurgical processes known and has been used for the recovery of dissolved metal values from leach solutions, as well as for the purification of electrolytes. Cementation has been extensively applied for the recovery of gold and silver from cyanide solutions, typically followed by the production of Dore metal, which is known as the Merrill-Crowe process. Although cementation of precious metals is widely used in the metallurgy industry, most of the articles published on cementation of gold and silver until about 1980 dealt only with plant practice. Scientific detailed laboratory investigations of the cementation reaction have only been reported during the past three decades. Studies of gold and silver have mostly been confined to the kinetics of gold and silver cementation on rotating discs or cylinders [5].

In spite of this research effort, the mechanistic details of the reactions taking place during cementation and the role of various species in solution in promoting or inhibiting the recovery of precious metals have received little attention and are still somewhat unclear. For example, it is generally accepted that cementation is sensitive both to the alkalinity and to the free cyanide concentration in solution. However, suitable experimental data are not available to describe plant practice in any detail. Only a few fundamental studies have been carried out in the recent past and also, until now, no detailed research has been reported regarding the morphological influence of the deposit structure on the cementation rate.

\subsection{Review of Cementation Phenomena}

In cementation reactions the metal to be reduced from aqueous solutions is more noble, having a greater electron affinity, than the precipitating metal. For example, the recovery or metallic silver by cementation with zinc dust is an electrochemical process involving the oxidation of zinc and the reduction of the silver cyanidation. The overall stoichiometry for the reaction in the case of silver is as follows:

$$
2 \mathrm{Ag}(\mathrm{CN})_{2}^{-}+\mathrm{Zn}=2 \mathrm{Ag}+\mathrm{Zn}(\mathrm{CN})_{4}^{-}
$$

A similar reaction can be written for gold precipitation. Silver is deposited at cathodic surface sites while zinc dissolves from anodic sites, and electrons are conducted 
between the two metallic phases as shown in Figure 1.

\subsection{Cementations Kinetics}

Considerable research has been reported on the characteristic features and mechanistic details of cementation reactions and this literature has been reviewed in terms of electrochemical theory and transport phenomena on several occasions [6].

In most cases, the cementation reactions follow firstorder reaction kinetics and generally are limited by diffusion of the noble metal ion through the mass-transfer boundary layer. In some cases the structure and morphology of the reaction product can have a significant effect on passivating the surface in other cases.

Most of the cementation reactions are found to be firstorder diffusion processes [7] with respect to the noble metal ion, and the reaction velocity constant, $\mathrm{k}$, for such a reaction may be computed from the general first-order rate equation:

$$
\frac{\mathrm{dc}}{\mathrm{dt}}=\frac{-\mathrm{kAC}}{\mathrm{V}}
$$

If $\mathrm{k}$ is not concentration dependent and the area is unchanging, Equation (5) may be integrated resulting in the integrated first-order expression,

$$
\log \frac{\mathrm{C}}{\mathrm{C}_{\mathrm{o}}}=-\frac{\mathrm{kAt}}{2.3 \mathrm{~V}}
$$

where $\mathrm{C}$ and $\mathrm{C}_{\mathrm{o}}$ are the noble metal concentrations at tine $\mathrm{t}$ and the initial concentration at time $\mathrm{t}=0$, respectively;

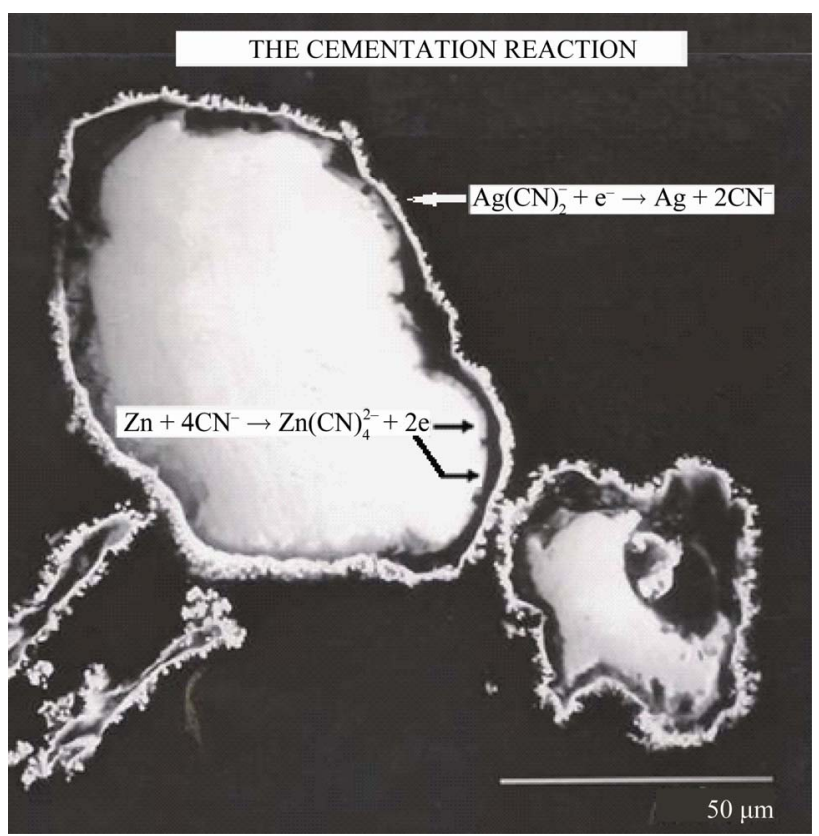

Figure 1. Electrochemical reaction of cementation of silver on zinc particle. $\mathrm{k}$ is the reaction velocity constant $(\mathrm{cm} / \mathrm{sec})$; $\mathrm{A}$ is reaction surface area $\left(\mathrm{cm}^{2}\right)$; and $\mathrm{V}$ is the solution volume rate $\left(\mathrm{cm}^{3}\right)$. In Equation (5), it can be seen that the cementation rate is a function of the reaction area $\mathrm{A}$. it has been shown by many investigators that in almost all cementation systems the initial exposed geometric area of the precipitant metal can be used in the analysis of initial rate data. However, in a more general sense, the area term is not always that simple to evaluate due to the changing nature of the noble metal deposit which grows on the active metal during the course of the reaction.

Experimental investigations [7] indicate that most cementation reactions are controlled by a mass transfer process, film diffusion, as indicated by the results presented in Table 1.

Notice in Table 1, that for almost all the cementation systems the apparent activation energy is in the range 2 $6 \mathrm{kcal} / \mathrm{mole}$ which would suggest that the cementation reactions are limited by mass transfer in the aqueous phase, with some exceptions $\left(\mathrm{Pb}^{2+} / \mathrm{Fe}\right.$ and $\left.\mathrm{Pb}^{2+} / \mathrm{Cu}\right)$. Also the reaction velocity constants are of the order $10^{-2}$ $\mathrm{cm} / \mathrm{sec}$ which also supports the position that these cementation reactions are mass transfer controlled.

\subsection{The Electrocoagulation Technology}

Electrocoagulation (EC) has been known as an electrochemical phenomenon since the last century. It has been employed previously for treating many types of waste-

Table 1. Data for selected cementation aqueous systems at $25^{\circ} \mathrm{C}$ [7].

\begin{tabular}{cccc}
\hline System & $\Delta \mathbf{E}_{\mathbf{o}}, \mathbf{V}$ & $\begin{array}{c}\text { Activation Energy, } \\
\text { Kcal/mole }\end{array}$ & $\begin{array}{c}\text { Reaction Velocity } \\
\text { Constant, cm/sec }\end{array}$ \\
\hline $\mathrm{Ag}^{+} / \mathrm{Cu}$ & 0.46 & $2.0-5.0$ & $2.5-6.0 \times 10^{-2}$ \\
$\mathrm{Ag}^{+} / \mathrm{Cu}\left(\mathrm{CN}^{-}\right)$ & 1.83 & $3.7-5.8$ & $1.5 \times 10^{-2}$ \\
$\mathrm{Ag}^{+} / \mathrm{Fe}\left(\mathrm{Cl}^{-}\right)$ & 1.29 & 3.0 & $2.2 \times 10^{-2}$ \\
$\mathrm{Ag}^{+} / \mathrm{Zn}\left(\mathrm{CN}^{-}\right)$ & 0.95 & 5.5 & $5.5 \times 10^{-2}$ \\
$\mathrm{Ag}^{+} / \mathrm{Zn}$ & 1.56 & $2.0-6.0$ & $2.6-5.2 \times 10^{-2}$ \\
$\mathrm{As}^{3+} / \mathrm{Cd}$ & 0.65 & $3.1 \pm 1.3$ & $7 \times 10^{-3}$ \\
$\mathrm{Au}^{+} / \mathrm{Zn}(\mathrm{CN})$ & 0.61 & 3.1 & $1.7 \times 10^{-2}$ \\
$\mathrm{Bi}^{3+} / \mathrm{Fe}$ & 0.76 & $4.5-7.6$ & $2.9 \times 10^{-2}$ \\
$\mathrm{Cd}^{2+} / \mathrm{Zn}$ & 0.36 & $4.0-4.7$ & $0.54-1.1 \times 10^{-2}$ \\
$\mathrm{Cu}^{2+} / \mathrm{Fe}$ & 0.75 & $3.1-5.1$ & $0.6-0.9 \times 10^{-2}$ \\
$\mathrm{Cu}^{2+} / \mathrm{In}$ & 0.83 & 2.3 & $5.9 \times 10^{-2}$ \\
$\mathrm{Cu}^{2+} / \mathrm{Ni}$ & 0.57 & $2.7-3.7(14.2-19.0)$ & $0.25-1.0 \times 10^{-2}$ \\
$\mathrm{Cu}^{2+} / \mathrm{Zn}$ & 1.10 & 3.1 & $1.6-2.1 \times 10^{-2}$ \\
$\mathrm{Ni}^{2+} / \mathrm{Fe}$ & 0.21 & 7.0 & $1.4 \times 10^{-4}$ \\
$\mathrm{~Pb}^{2+} / \mathrm{Fe}$ & 0.31 & 12.0 & - \\
$\mathrm{Pb}^{2+} / \mathrm{Zn}$ & 0.64 & - & $0.64 \times 10^{-2}$ \\
$\mathrm{~Pb}^{2+} / \mathrm{Cu}$ & 0.49 & $9.5-7.4$ & $0.36-2.3 \times 10^{-2}$ \\
\hline & & &
\end{tabular}


water with varying degrees of success [8-10]. The EC process can be considered as an acelerated corrosion process was green rust (GR) is an intermediate product that is responsible for the removal of contaminants (suspended and dissolved solids, metals, organic compounds, etc). EC mechanisms may involve oxidation, reduction, decomposition, deposition, coagulation, absorption, adsorption, precipitation and flotation. EC operates on the principle that hidrolized cations produced electrolytically from iron and/or aluminum anodes enhance the coagulation of contaminants from an aqueous medium.

The sacrificial metal anodes are used to continuously produce polyvalent metal cations in the vicinity of the anode. These cations facilitate coagulation by neutralizing the negatively charged particles that are carried toward the anodes by electrophoretic motion. Generally in the EC process bipolar electrodes are used [9-11]. It has been reported that cells with bipolar electrodes connected in series operating at relatively low current densities produced iron or aluminum coagulant more effectively. In the EC technique, the production of polyvalent cations from the oxidation of the sacrificial anodes ( $\mathrm{Al}$ or $\mathrm{Fe}$ ) and the production of electrolysis gases $\left(\mathrm{O}_{2}\right.$ and/or $\left.\mathrm{H}_{2}\right)$ are directly proportional to the amount of current applied (Faraday's law). The electrolysis gases enhance the flotation of the coagulant material. A schematic representation of the EC process, using iron electrodes, is shown in Figure 2. As mentioned above, the gas bubbles produced by electrolysis carry the gold and silver along with the sludge to the top of the solution where it is collected and removed.

However, it is the reactions of the metal ions that enhance the formation of the coagulant. The metal cations are hydrolyzed, releasing hydrogen ions that result in hydrogen evolution at the cathode, to yield both soluble and insoluble hydroxides that will react with or adsorb gold and silver from the cyanide solution and also contribute to coagulation by neutralizing the negatively charged colloidal particles that may be present at neutral

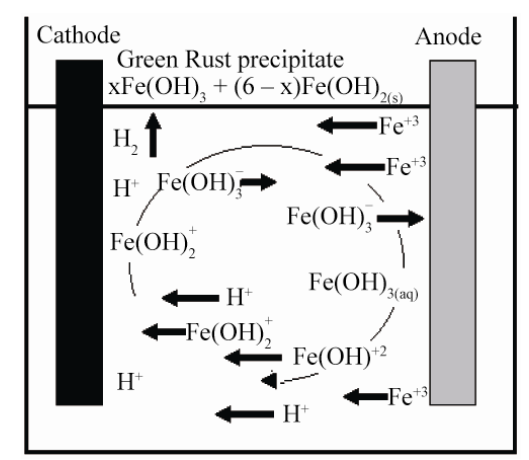

Figure 2. An illustration of the EC mechanism (arrow indicate the migration of ions, the $\mathrm{H}_{2}$ evolution and the formation of green rust). or alkaline $\mathrm{pH}$.

This enables the particles to approach closely and agglomerate under the influence of Van der Waals attractive forces. The chemical reactions that have been proposed to describe EC mechanism [12] when using iron electrodes are:

$$
\begin{gathered}
\mathrm{Fe} \leftrightarrow \mathrm{Fe}^{+3}+3 \mathrm{e}^{-} \\
\mathrm{Fe}(\mathrm{OH})^{+2}+\mathrm{H}_{2} \mathrm{O} \rightarrow \mathrm{Fe}(\mathrm{OH})_{2}^{+1}+\mathrm{H}^{+} \\
2 \mathrm{H}^{+}+2 \mathrm{e}^{-} \rightarrow \mathrm{H}_{2(\mathrm{~g})} \uparrow \\
\mathrm{Fe}(\mathrm{OH})_{2}^{+1}+\mathrm{e}^{-} \rightarrow \mathrm{Fe}(\mathrm{OH})_{2(\text { aq })} \\
\mathrm{Fe}(\mathrm{OH})_{2(\text { aq })}+\mathrm{H}_{2} \mathrm{O} \rightarrow \mathrm{Fe}(\mathrm{OH})_{3}^{-1}+\mathrm{H}^{+} \\
\mathrm{Fe}(\mathrm{OH})_{3}^{-1} \rightarrow \mathrm{Fe}(\mathrm{OH})_{3(\text { aq })}+\mathrm{e}^{-}
\end{gathered}
$$

\section{Overall reaction}

$$
\begin{aligned}
6 \mathrm{Fe}+(12+\mathrm{x}) \mathrm{H}_{2} \mathrm{O} & \rightarrow \frac{1}{2}(12-\mathrm{x}) \mathrm{H}_{2(\mathrm{~g})} \uparrow \\
+ & x \mathrm{xe}(\mathrm{OH})_{3} \times(6-\mathrm{x}) \mathrm{Fe}(\mathrm{OH})_{2(\mathrm{~s})}
\end{aligned}
$$

The $\mathrm{pH}$ of the medium usually rises as a result of this electrochemical process and the Green Rust formed $\left[\mathrm{xFe}(\mathrm{OH})_{3} \times(6-\mathrm{x}) \mathrm{Fe}(\mathrm{OH})_{2(s)}\right]$ remains in the aqueous stream as a gelatinous suspension, which can remove the gold and silver from pregnant cyanide rich solutions, either by complexation or by electrostatic attraction of magnetic nanoparticles followed by coagulation and flotation. Generally, in the EC process, bipolar electrodes are used [8]. It has been reported that cells with bipolar electrodes, connected in series operating at relatively low current densities, produce iron or aluminum coagulant more effectively, more rapidly and more economically when compared to chemical coagulation.

\section{Experimental Procedures}

\subsection{Suspended Zinc Particle Experiments}

The bath reactor experiments were done in four-necked, one liter glass reaction cells supported in a constant temperature bath. A condenser, stirrer, nitrogen dispersion tube, and sampling derive were placed into a reactor through the openings in the lid. The Teflon stirrer was attached through the center port by means of a Chesapeak stirrer connection. In all studies purified nitrogen was passed through the solution, via a dispersion tube, before and during the experiment to maintain an oxygenfree environment. Tyler sieves were used to prepare monosize fractions of zinc in the range from 70 to 400 mesh.

The specific surface area of the zinc dust was measured using two techniques, the BET technique (Quan- 
tasorb Model 0S10, made by Quantachrome Corporation), surface area $255 \mathrm{~cm}^{2} / \mathrm{gr}$, and the air permametry technique (Permaran made by Outokumpu), surface area 216 $\mathrm{cm}^{2} / \mathrm{gr}$. The stirring speed was adjusted manually (1000 RPM) and was checked with a stroboscope. The particulate sample of zinc was washed with acetone and cleaned with acid to remove the surface oxide film before being introduced into the reaction flash. For most of the experiments, one gram of $270 \times 400$ mesh $\left(\mathrm{d}_{50}=45 \mu \mathrm{m}\right)$ particles of zinc were introduced through one of the cover ports, and the reaction was initiated. In order to follow the course of cementation reaction, solution aliquots of $2 \mathrm{ml}$ were taken periodically and analyzed for silver and gold with a DCP (Direct-Current Plasma) Spectrophotometer manufactured by Beckman Instruments.

\subsection{Experimental Electrocoagulation Details}

The EC experiments were performed in a $400 \mathrm{ml}$ beaker size reactor equipped with two carbon steel electrodes (6 $\mathrm{cm} \times 3 \mathrm{~cm}$ ) that were $5 \mathrm{~mm}$ apart. As a source of current and voltage a universal AC/DC adaptor was used. $\mathrm{pH}$ was measured with a VWR scientific $8005 \mathrm{pH}$ meter. Gold and silver adsorption onto iron species was investigated with pregnant cyanide solutions provided by Bacis S. A. de C. V. mining group (13.25 ppm Au and 1357 $\mathrm{ppm} \mathrm{Ag}$ and $\mathrm{pH}$ of 8). Analyses were performed by ICP/ Atomic Emission Spectrometry. The conductivity of pregnant solutions was adjusted by adding one gram of $\mathrm{NaCl}$ per liter (Fisher, $99.8 \%$ A. C. S. Certified, lot \#995007).

To identify and characterize the iron species in the solid products, formed during the EC process for the removal of gold and silver using iron electrodes, X-ray diffraction (XRD) and Scanning Electron Microscope (SEM/EDX) were used. Analysis of $\mathrm{Au}$ and $\mathrm{Ag}$ were conducted to the Bacis solution, by AES. EC was run at 15 Volts (DC) and the corresponding current was of 0.1 $\AA$ A. EC was run for five minutes, and a sample was taken every minute in order to determinate the removal efficiency for $\mathrm{Au}$ and $\mathrm{Ag}$. Solutions and solids from the EC process were separated by filtration through cellulose filter paper. The sludge from the EC was dried either in an oven or under vacuum at room temperature and characterized.

\section{Results and Discussion}

\subsection{Zinc Dust Particle Size Results}

As was shown by Equation (5), the rate of cementation reaction is expected to be a function of the surface area and the concentration of the reacting noble metal ion (gold or silver in the present case). To examine the traditional first order rate expression, the cementation reaction kinetics were studied using monosize zinc particles. Two experiments were conducted at $10 \mathrm{ppm}\left(5 \times 10^{-5} \mathrm{M}\right)$ gold and $100 \mathrm{ppm}\left(9 \times 10^{-4}\right)$ silver in order to study the reaction kinetics at these concentrations. The equilibrium concentration profiles (on logarithmic scale), the results were found to conform to the first-order rate process for over 99\% removal as shown in Figure $3\left(\mathrm{Au} / \mathrm{Zn}(\mathrm{CN})^{-}\right.$ system) and $\left(\mathrm{Ag} / \mathrm{Zn}(\mathrm{CN})^{-}\right.$system). From these data it is evident that the cementation of both gold and silver by zinc conforms to well-behaved fist order kinetics. Also, from these figure, the micrograph of reacted zinc particles can be seen. This micrograph reveals the nature of the silver and gold deposits. The effect of the gold and silver deposits on the rate of cementation reaction product showed that the gold and silver formed uniforms, apparently porous layer around the zinc particle. Table 2 lists the values of the reaction velocity constant for the cementation of gold $(10 \mathrm{ppm})$ and silver $(100 \mathrm{ppm})$ on zinc dust.

\subsection{Electrocoagulation Results}

Running the EC process for gold and silver removal on iron electrodes, gave the results shown in Table 3 and in Figure 4, shows the equilibrium concentration profile of gold and silver removal efficiency and final $\mathrm{pHs}$ values vs Time. The obtained results show that EC is an excellent option to remove $\mathrm{Au}$ and $\mathrm{Ag}$ from cyanide pregnant solution by using iron electrodes. Also, under these conditions, the results show that, when residence time increases from 1 to 3 minutes the silver and gold removal increase to $92 \%$ and $99 \%$ respectively, this variation occurs at $\mathrm{pH}$ values from 9 to 10.7, approximately; these values coincide with the production of magnetic iron, $\mathrm{Fe}_{3} \mathrm{O}_{4}$ (green rust). Also, it is apparent that the uptake percents of gold/silver increased by increasing the $\mathrm{pH}$ value.

The mechanism of the EC process for gold and silver

Table 2. Comparison of experimental reaction velocity constants with calculated mass-transfer coefficients for suspended particles. $\mathrm{NaCN}=10^{-2} \mathrm{M} ; \mathrm{pH}=10.5 ;$ Stirring speed $=1000 \mathrm{rpm} ; \mathrm{Au}=10 \mathrm{ppm}\left(5 \times 10^{-5} \mathrm{M}\right) ; \mathrm{Ag}=100 \mathrm{ppm}\left(9 \times 10^{-4} \mathrm{M}\right)$.

\begin{tabular}{cccc}
\hline System & Particle size, mesh & Experimental reaction velocity constant, cm/sec & Calculated mass-transfer coefficient \\
\hline $\mathrm{Au} / \mathrm{Zn}(\mathrm{CN})^{-}$ & $400 \times 270$ & $1.9 \times 10^{-2}$ & $2.35 \times 10^{-2}$ \\
$\mathrm{Ag} / \mathrm{Zn}(\mathrm{CN})^{-}$ & $400 \times 270$ & $1.62 \times 10^{-2}$ & $3.2 \times 10^{-2}$ \\
\hline
\end{tabular}




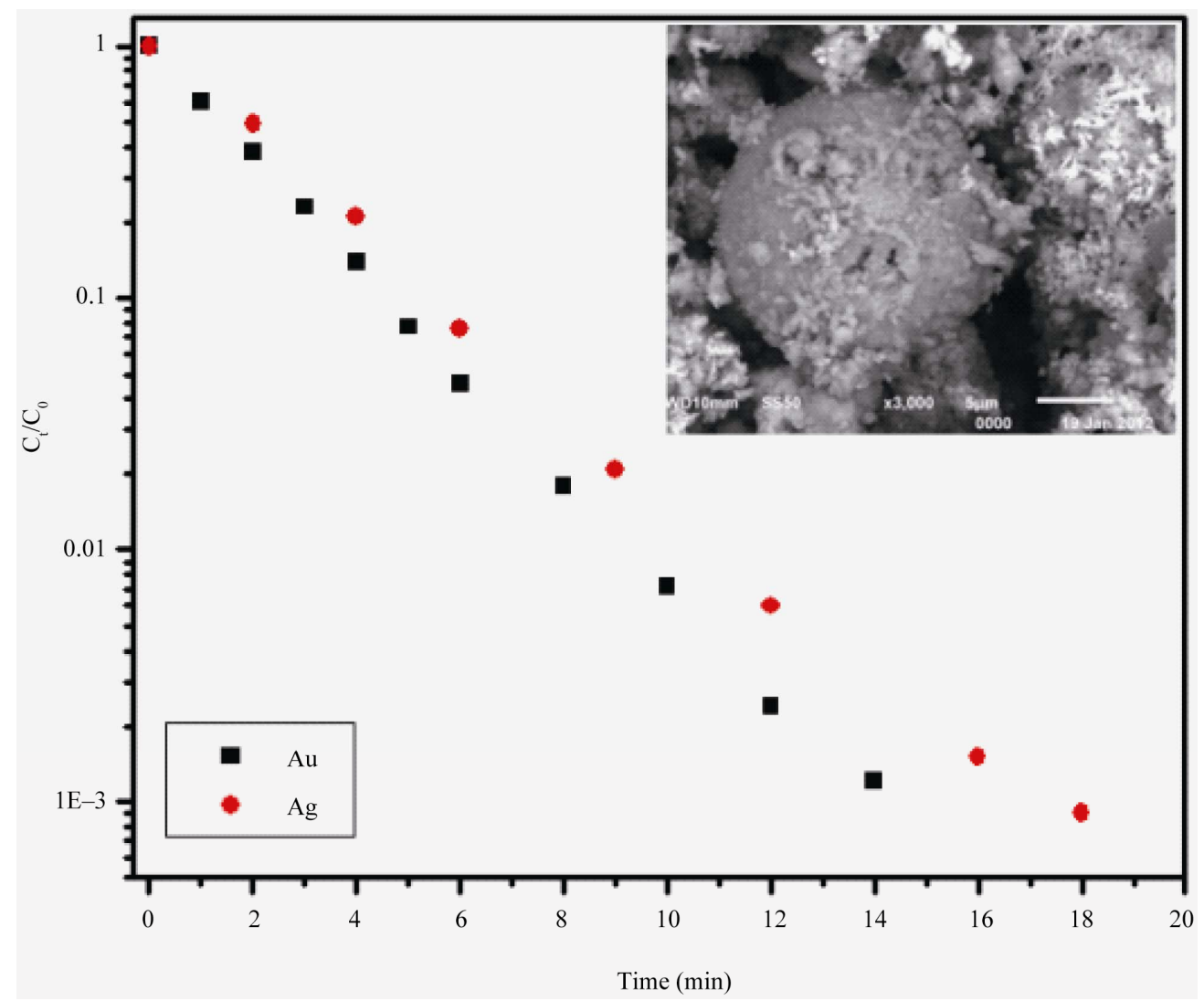

Figure 3. First-order plots showing removal of gold and silver from cyanide solution.

Table 3. Recovery of gold and silver by EC.

\begin{tabular}{cccccc}
\hline $\begin{array}{c}\text { EC residence } \\
\text { time }(\mathbf{m i n})\end{array}$ & $\begin{array}{c}\text { Au } \\
\left(\mathbf{m g} \cdot \mathbf{L}^{-\mathbf{1}}\right)\end{array}$ & $\begin{array}{c}\text { Recovery } \\
\mathbf{( \% )}\end{array}$ & $\begin{array}{c}\mathbf{A g} \\
\left(\mathbf{m g} \cdot \mathbf{L}^{-\mathbf{1}}\right)\end{array}$ & $\begin{array}{c}\text { Recovery } \\
\mathbf{( \% )}\end{array}$ & $\mathbf{p H}$ \\
\hline 0 & 13.25 & 0 & 1357.0 & 0 & 8.0 \\
1 & 12.50 & 5.66 & 940.0 & 30.72 & 9.2 \\
2 & 10.50 & 20.37 & 219.5 & 83.82 & 9.5 \\
3 & 1.00 & 92.45 & 9.0 & 99.33 & 10.7 \\
4 & 0.50 & 96.22 & 7.0 & 99.48 & 11.2 \\
5 & 0.10 & 99.24 & 0.9 & 99.93 & 11.5 \\
\hline
\end{tabular}

recovery is then physical and chemical adsorption, caused by the highly reactive species and adsorption properties of green rust. These processes do not alter their chemical composition. Figure 4, also shows graphically the $\mathrm{pH}$ during the EC the process for gold and silver removal, the $\mathrm{pH}$ increment in the solution from 8 to a $\mathrm{pH}$ final of 11 is attributed to the hydrogen evolution at the cathode which is then accompanied by alkalinization of the aqueous solution.

\subsection{Product Characterization}

$X$-ray Diffraction Analysis. Diffraction patterns of flocs collected from the experiment with gold and silver, (the sample were ground to a fine powder and loaded into a sample holder) were obtained with a diffracted X-PERT Phillips meters equipped with a vertical goniometer, with a range of analysis $2 \theta 10^{\circ}$ to $70^{\circ}$. The source of X-rays has a copper anode, whose radiation is filtered with a graphite monochromator $(\lambda=1.541838 \AA$ ) with scan rate of $0.02^{\circ}$ and a duration of 10 seconds per count. The X-ray Diffractometer is controlled by a Gatawey 2000 computer, by PC-APD 2.0 with software for Windows.

Figure 5 shows the ray diffraction pattern of the flocs recovered from the sample of gold and silver, respectively $13.25 \mathrm{mg} / \mathrm{L}$ and $1357 \mathrm{mg} / \mathrm{L}$, initial $\mathrm{pH} 8,5$ minutes of treatment, 0.1 amperes and 15 volts. The species identified were magnetite, lepidocrocite, goehtite, silver and copper hexacyanoferrate. Scanning Electron Microscopy (SEM/EDAX). Figure 6 shows SEM images and EDAX of silver adsorbed on iron species. These SEM and EDAX results show that the surfaces of these iron oxide/oxyhydroxide particles were coated with a layer of silver. It is worth clarifying that, given the low concentration of gold it was impossible to locate any nanoparticle of it.

\section{Conclusion}

The cementation of both gold and silver by suspended zinc particles conforms to well-behaved fist order kinet- 


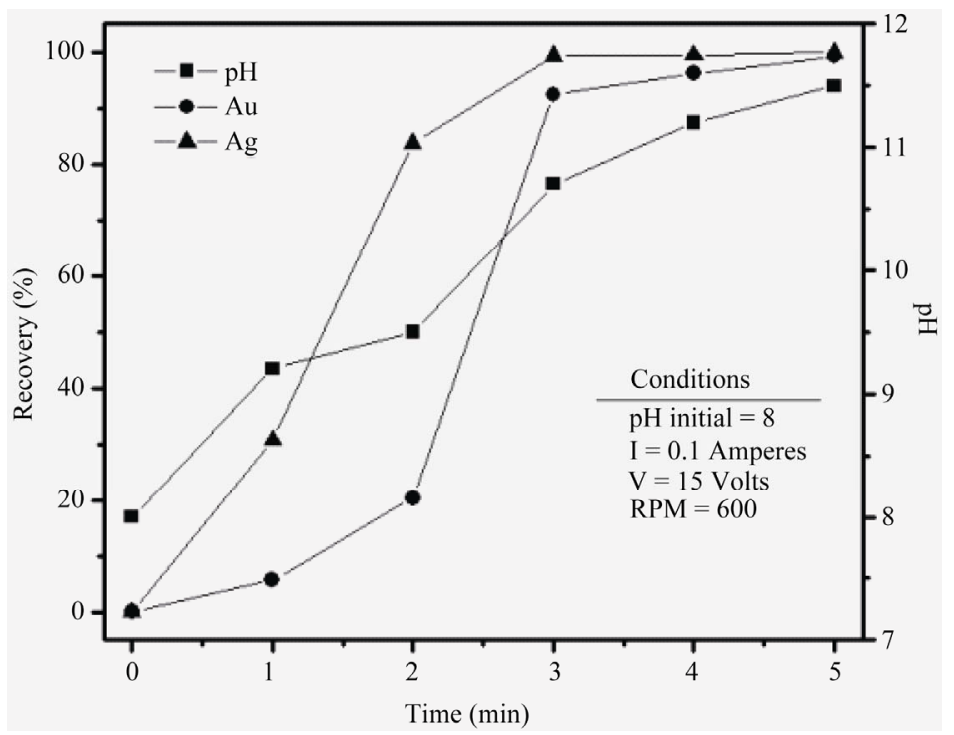

Figure 4. Gold and silver recoveries from Bacis cyanide solutions and pH vs EC residence time.

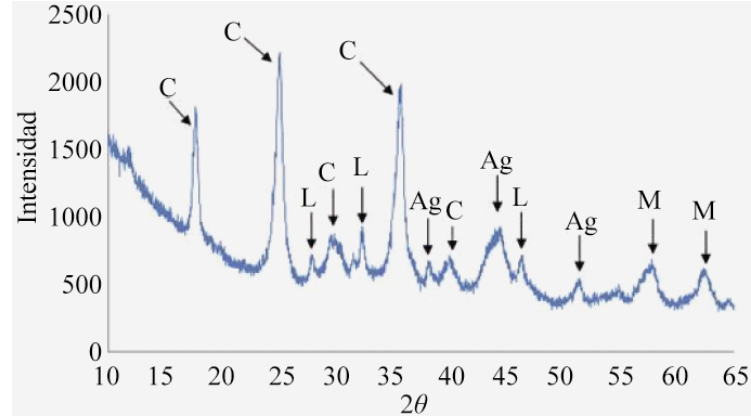

Figure 5. X-ray diffractogram of solids obtained in the recovery of gold and silver $\mathrm{C}$ : $\mathrm{Cu}_{2} \mathrm{Fe}(\mathrm{CN}) 62 \mathrm{H}_{2} \mathrm{O}$, A: Silver, $\mathrm{M}$ : Magnetite and L: Lepidocrocite.

ics. The effect of the gold and silver deposits on the rate of cementation reaction product showed that the gold and silver formed uniforms, apparently porous layer around the zinc particle. The experimental reaction velocity constants correspond to the expected magnitude of the limiting mass-transfer coefficients and support the hypothesis that the cementation reactions under these conditions are mass-transfer limited reactions with recoveries of gold and silver of $99.8 \%$. The obtained results show that EC process is an excellent option to remove $\mathrm{Au}$ and $\mathrm{Ag}$ from cyanide pregnant solution by using iron electrodes. The X-ray Diffraction, Scanning Electronic Microscopy, techniques demonstrate that the formed species are of magnetic type, like lepidocrocite and magnetite, and amorphous iron oxyhydroxide which adsorbed the silver and gold particles on his surface due to the electrostatic attraction between both metals. The $99.5 \%$ of gold and silver were removed in the experimental EC reactor, and it was achieved in 5 minutes or less with a current efficiency of $99.7 \%$.

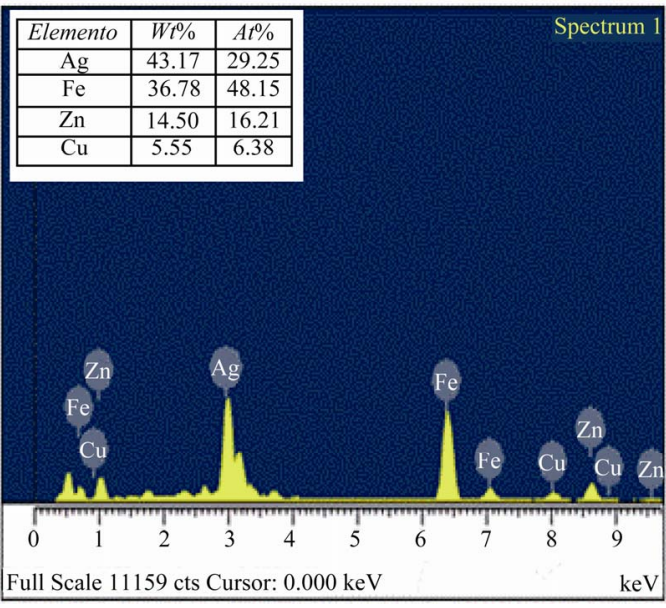

(a)

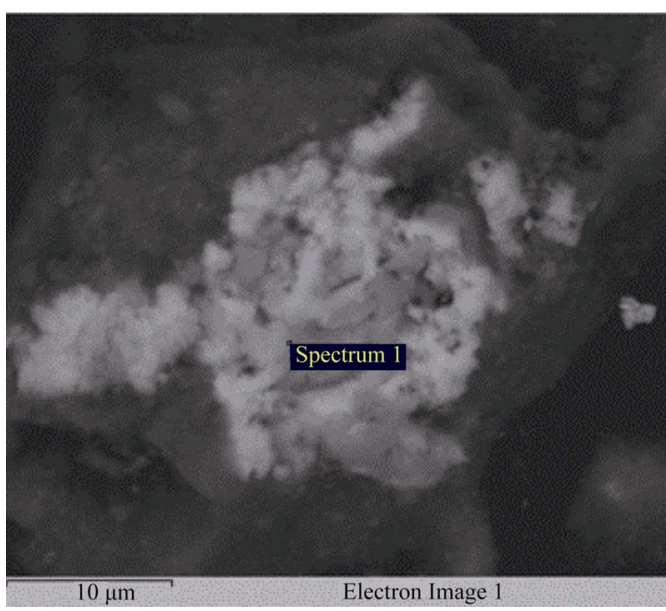

(b)

Figure 6. Chemical composition of solid product as determined by EDX, which shows the presence of silver in the particle of iron. 


\section{Acknowledgements}

The authors wish to acknowledge support of this project to the National Council of Science and Technology (CONACYT) and to Dirección General de Educación Superior Tecnológica (DGEST) from Mexico.

\section{REFERENCES}

[1] F. Habashi, "A Short History of Hydrometallurgy," Hydrometallurgy, Vol. 79, No. 1-2, 2005, pp. 15-22. doi:10.1016/j.hydromet.2004.01.008

[2] J. R. Parga, G. Gonzalez, H. Moreno and J. L. Valenzuela, "Thermodynamic Studies or the Strontium Adsoption on Iron Species Generated by Electrocoagulation," Desalination and Water Treatment, Vol. 37, No. 1-3, 2012, pp. 244-252.

[3] J. R. Parga, J. L. Valenzuela, H. Moreno and J. E. Perez, "Copper and Cyanide Recovery in Cyanidation Effuents," Advances in Chemical Engineering and Science, Vol. 1, No. 4, 2011, pp. 191-197. doi:10.4236/aces.2011.14028

[4] R. Woods, "Extracting Metals from Sulfide Ores," 2010. http://electrochem.cwru.edu/encycl/art-m02-metals.htm

[5] W. Wai, L. Eugene and A. S. Mujumdar, "Gold Extraction and Recovery Processes," 2009.

http://www.eng.nus.edu.sg/m3tc/M3TC Technical Repo rts/Gold\%20Extraction\%20and\%20Recovery\%20Process es.pdf

[6] F. Habashi, "Kinetics and Mechanism of Gold and Silver Dissolution in Cyanide Solution," Montana Bureau of
Mines Geological Bulletin, No. 59, 1967, pp. 1-42.

[7] S. Gamini, "The Cyanidation of Silver Metal: Review of Kinetics and Reaction Mechanism," Hydrometallurgy, Vol. 81, No. 2, 2006, pp. 75-85.

[8] J. R. Parga, D. L. Cocke, J. L. Valenzuela, H. Moreno and M. Weir, "Arsenic Removal via Electrocoagulation from Heavy Metal Contaminated Groundwater in La Comarca Lagunera Mexico," Journal of Hazardous Materials, Vol. 124, No. 1-3, 2005, pp. 247-254. doi:10.1016/j.jhazmat.2005.05.017

[9] M. Mollah, P. Morkovsky, J. Gomez, J. R. Parga and D. Cocke, "Fundamentals, Present and Future Perspectives of Electrocoagulation," Journal of Hazardous Materials, Vol. 114, No. 1-3, 2004, pp. 199-210. doi:10.1016/j.jhazmat.2004.08.009

[10] M. M. Emamjomeh and M. Sivakumar, "Review of Pollutants Removed by Electrocoagulation and Electrocoagulation/Flotation Processes," Journal of Environmental Management, Vol. 90, No. 5, 2009, pp. 1663-1679. doi:10.1016/i.jenvman.2008.12.011

[11] X. Zhao, B. Zhang, H. Liu and J. Qu, "Removal of Arsenite by Simultaneous Electro-Oxidation and ElectroCoagulation Process," Journal of Environmental Management, Vol. 184, No. 1-3, 2010, pp. 472-476. doi:10.1016/j.jhazmat.2010.08.058

[12] H. Moreno, D. L. Cocke, J. A. G. Gomes, P. Morkovsky, J. R. Parga, E. Peterson and C. Garcia, "Electrochemical Reactions for Electrocoagulation Using Iron Electrodes," Industrial \& Engineering Chemistry Research, Vol. 48, No. 4, 2009, pp. 2275-2282. doi:10.1021/ie8013007 